\title{
Renewable Electric Generation in a Pig's Farm from the Own Pig Slurry. Energy from biomass
}

\author{
H. Beltran, N. Aparicio, E. Belenguer \\ Dpt. Enginyeria de Sistemes Industrials i Disseny \\ Universitat Jaume I \\ Campus del Riu Sec - Av. Sos Baynat s/n \\ 12071 Castelló (SPAIN) \\ Phone/Fax Number: (+34) 964728178 / 964728170 \\ E-mail: hbeltran@esid.uji.es, aparicio@esid.uji.es, efbeleng@esid.uji.es
}

\begin{abstract}
This paper introduces the possibility of using a production waste, such as the pig slurry, obtained in the cattle raising industry in order to produce energy. Thermal and electric generation can be obtained by means of a cogeneration system and the two kinds of energy used in the industrial process itself. In this application case, energies would be used for pig slurry heating and to export electric current to the Electric Power System (EPS) respectively. The viability of creating a cogeneration unit in a farm, using the biogas (methane + carbon dioxide) generated by the fermentation, anaerobic digestion (AD), of the pigs slurry as fuel for the motor or turbine, is studied and proposed.
\end{abstract}

\section{Keywords}

Biomass, pig slurry, biomethanization, cogeneration, biogas plants.

\section{Introduction}

The new pig farm philosophy, in which thousands of animals are piled up together giving rise to regions with high densities of animals, allows thinking in a primary source of constant residue material in those areas in a quantity important enough to use it as fuel to feed a cogeneration motor. To get an idea, a little-medium size farm, as the one analysed in the paper with 1200 pigs, would produce $7344 \mathrm{~m}^{3}$ of slurry per year. Nothing compared with the $298 \times 106 \mathrm{~m}^{3}$ per year produced in the whole European Union. A volume that would fit on 20 meters wide motorway, along a $3145 \mathrm{~km}$ long stretch, and reaching the 5 meters of height. This is, potentially, a huge source of energy to be profited.

Traditionally, cattle raising residue, and more specifically the pig slurry, have been used as fertilizer due to its high content in organic components and mineral nutrients. However, the big increase during the last years in the number of intensive farms has resulted in a pig slurry production within small regions that can not be managed by traditional ways anymore. This is the case for the
Castelló interior northern shires where the pig slurry is a real problem. The agricultural lands in some villages have no enough surfaces to spread out all the pig slurry produced in their farms (since the maximum quantity of residue to dump in the fields is regulated).

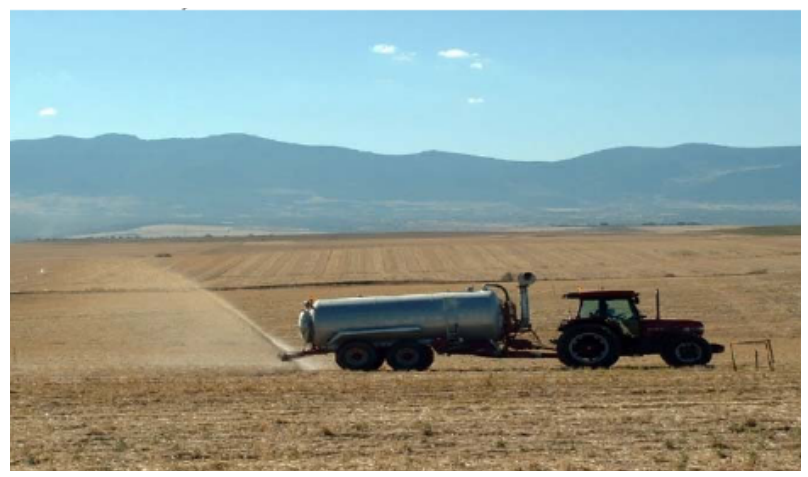

Fig. 1. Traditional way to apply pig slurry to the fields.

Thanks to the biogas installations, this big problem could be transformed into a business, supported by the actual regulations, generating electricity by cogeneration and creating employment in regions where the farm industry is one of the few sources of work. Thus, the authorities interested in projects such as this one would help to retain young population in the zone. Apart from these two aspects, by introducing the pig slurry in the biogas plant it gets purified and can be treated afterwards in many ways or used to irrigate the fields.

Another aspect that can help to establish this kind of installations is the need for electric production. Nowadays, electric consummation is increasing in our community an average of around the $6 \%$ per year, probably influenced by the increase in the construction and tourism sectors. And, on the other hand, the autonomic authorities are taking all kind of initiatives to reach the self production, which has been traditionally loss-making. In this situation, every kind of electric generator solution will be politically accepted and 
supported if technically and economically is demonstrated to be feasible.

In this way, the paper tries to give an example of green power production plant to a static sector, as the farmer's one is, and for the authorities. It is the example of the typical small biogas plant which could solve serious environmental problems, related with the slurry, while producing energy at very low cost. Therefore, a prototype plant has been designed to give ideas about how diversifying farmer's business increasing in this way the economic benefits for all the parts of taking part in this new industry

Moreover, the energy production from biomass is one of the weak points in the renewable energies plan promoted by the Spanish minister to achieve the goal of producing the $12 \%$ of the total production in the year 2012 from renewable sources. This plan tries to reduce the energy exterior dependence of the country at the same time than diversifying the sources of energy and looking for the creation of a national industry in the renewable energies sector. Some technologies, as it is the case for the wind power generation, are completing their objectives whilst others, such as biomass, are not evolving as expected. Hence, the paper tries to convince about the feasibility of this kind of projects and promote deployment of $\mathrm{AD}$ plants, stimulating at the same time interaction between R\&D programs, and the industry and decision makers of the sector.

Then, the principal aim of this paper is to exchange and disseminate information on biogas production from biomass and, on a proper way to use its energy. This work is focused on the methodology of the international energy agency and its IEA Bioenergy tasks 24 and 37 [1],[2]. In that way, it tries to resume and evaluate the environmental and economical viability of using the pig slurry in order to construct a cogeneration plant which would burn the biogas $\left(\mathrm{CH}_{4}+\mathrm{CO}_{2}\right)$ obtained from the anaerobic digestion of this kind of biomass.

\section{Regulatory frame}

For this kind of projects a great deal of legislation has to be taken into account since they are related with different domains of the industry and the society. The two main aspects to take into account are: the environment and the energy, with their corresponding legislations.

\section{A.Environmental regulations}

Many different regulations refer to the management of the residue, comprehending from the EU level to the local regulations. Some have to be highlighted, such as the Directive 91/61/UE relative to the integrated prevention and control of the pollution and the Directive 91/676/CEE, relative to the water protection against agricultural pollution. This second one refers directly to the generation of pig slurry. Finally, the Directive 91/156/UE which regulates the residue and has been transposed to the Spanish regulation by the National Law $10 / 1998$ [3] is of importance too.

Regarding the Spanish situation, apart from the residue law there is a Spanish Real Decreto (RD) which has a huge importance in the cattle raising sector, establishing the different types of farms and the slurry production estimated for each of them; it is the RD 436/2004 [4].

Finally, the autonomic administration in the Valencian Community has set up a general plan for the management of the residue that applies too [7]. This plan proposes the installation of several biogas plants in order to give value to the pig slurry produced during the cattle raising in the northern shires, but only for zones with lands having nutrients enough, preferring the production of compost or liquid manure in any other case. The treatment plants considered for its implementation are:

\begin{tabular}{|c|c|c|}
\hline Shire & $\begin{array}{c}\text { Installation } \\
\text { Type }\end{array}$ & $\begin{array}{c}\text { Capacity } \\
\text { Tm/day }\end{array}$ \\
\hline L'Alcalaten; La Plana Alta & Compost Plant & 500 \\
\hline Alto Palancia & Compost Plant & 150 \\
\hline Els Ports & Biogas Plant & 700 \\
\hline Baix Maestrat & Biogas Plant & 1.300 \\
\hline TOTAL & & $\mathbf{2 . 6 5 0}$ \\
\hline
\end{tabular}

TABLE 1 - Programmed plants on autonomic regulations.

However, nothing has been done in this field up to the moment.

\section{B.Energy regulations}

For the analysis of the energy regulations, a similar procedure has been done revising from EU regulations to autonomic ones. Among the different European directives, two of them are underlined affecting a biogas plant with electric generation:

- Directive 2003/54/CE, with common rules for the inner electric markets.

- Directive 2001/77/CE, relative to the promotion of the electric current generated from renewable sources.

The main measures to promote renewable energies in Spain arrive with the National Law 54/1997 [8], and get concrete with the publication on December the 31st of the $\mathrm{RD} 2818 / 1998$, around production of electric energy by installations fed by renewable resources, residue and cogeneration. This RD was modified and amplified by the most important one, the RD 436/2004 0 that together with the National Plan of Renewable Energies establish the methodology for the actuation and systematization of the juridical and economical system of the electric energy production activity under especial conditions, or renewable resources, residue and cogeneration. This last $\mathrm{RD}$ is the one that fixes the bonus that the biogas plants will receive.

The autonomic authorities have promoted laws and regulations to prompt electric generation from renewable forces, such as a plan for wind generation or a plan for 
energy efficiency, but none of them applies for the production from biomass.

\section{Actual situation of the sector}

Nowadays, the EU is the pork export trade world leader, although its importance is decreasing arriving just to the $34 \%$ of the global commerce in 2005. During the last years, the USA have reinforced their position in the market, becoming established in the second position in front of Canada. It is to outline in the international context the irruption of countries such as Brazil and China as new export trade references. Nevertheless, factors related with environment, costs and labour will define the map of the pork world trade in the next years as well as evolution of the developing countries.

Referring to the Spanish pork sector, it meant along 2005 an overall volume of trade of 4459 ' 7 millions of euros, supposing the 31 '3\% of the total final cattle production. This economical sector employs among 130000 and 150000 workers directly or indirectly. The number of pigs entered in the accounts last year got up to 24889 thousands of animals (decreasing a $-0.03 \%$ referring to 2004). This amount represents the $16.4 \%$ of the total European number. The Spanish pork production in 2005 reached the 3164000 Tones (-0.4\% referring to 2004), the $15 \%$ of the total European production [6].



Fig. 2. Distribution of the Spanish Pig Population in the different autonomous communities.

Regarding the Spanish interior market, the production is quite divided among different autonomous communities, Fig. 2, being especially important the production in Catalonia with more than 6.3 millions of pigs. As this paper studies the case of a farm in Castelló, it is interesting too to analyze the pork production in the Valencian Region and how its more than 1.9 million pigs are distributed in the three different provinces, Fig. 3.

As it can be clearly extracted from Fig. 3 the importance of Castelló with more than a million of pigs (number which varies every year). That is why the project has been thought for a farm in that province. This quantity of animals in a province quite small, being most of the farms concentrated in just some northern shires, allows thinking on a problem with their pig slurry.

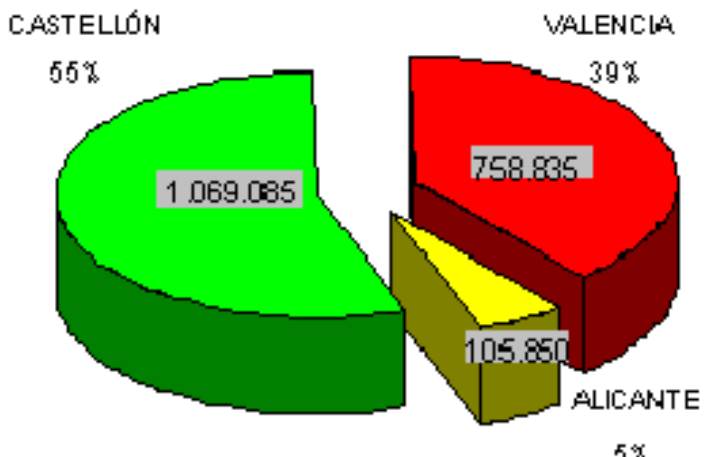

Fig. 3. Pig slurry production (in Tones) in the Valencian autonomous community in 2005.

In order to study the possible locations where a biogas plant could be introduced to solve some problems, a more detailed distribution of the cattle farms concentration in the province of Castelló can be encountered. In the following list, the number of farms with their corresponding number of animals and the type of production they follow are posted from the data collected along 2003. For that year, the accounts show an overall of 1078 existing farms with a total of 728600 :

- 506 fatten farms with 497515 pigs.

- 160 piglet production farms with 23791 animals.

- 205 closed-cycle farms with 26875 animals.

- 161 closed or mixed-cycle with 156174 animals.

- 46 farms with other finalities with an overall of 24616 animals.

Thus, many of them could adopt a biogas plant as a solution or even a concentration of farms could join to create a bigger and more efficient plant.

\section{Description of the farm studied}

The farm considered for the prototype project is located in the village of Rossell, north of Castelló, and it is dedicated to the production and raise of piglets up to $20 \mathrm{~kg}$. It has authorization to produce 360UGMs where UGM stands for unit equivalent to bovine adults. This represents the restriction established by the authorities to the new exploitations due to the excess in residue already existing. No new farms can be established if they do not provide solutions for their residue or buy the license and the corresponding UGMs to another farm already under functioning.

With this data, knowing the permissions the farm has, it is easy to extract the quantity of pigs that they can contain after the Table 2, corresponding to the RD 324/2000 already introduced.

$$
\frac{360 U G M}{0.3}=1200 \text { pigs }
$$

So, that is the quantity of adult pigs with their piglets in production in the farm. With the same table it is easy to 
determine the quantity of pig slurry produced by the whole farm along the year.

$$
1200 \text { pigs } \times 6.12 m^{3} / \text { pig } \cdot \text { year }=7344 m^{3}
$$

And that is the volume to be treated and profited. The quantity of methane produced from the solid fraction of the pig slurry is, from experimental results, $0.4 \mathrm{~m}^{3} / \mathrm{kg}$. And knowing the quantity of solids in the residue from table 3 and the density of it equal to $1010 \mathrm{~kg} / \mathrm{m}^{3}$, the total annual volume of methane produced can be determined.

TABLE 2 - Quantity of liquid by product and UGM equivalence for the different types of pig cattle.

\begin{tabular}{|c|c|c|}
\hline Type of animal & $\begin{array}{c}\text { Liquid and } \\
\text { semi liquid } \\
\text { manure } \\
\text { (m³/year) }\end{array}$ & $\begin{array}{c}\text { UGM } \\
\text { Equivalence }\end{array}$ \\
\hline Closed cycle pig & 17,75 & 0,96 \\
\hline Pig with piglets up to $6 \mathrm{~kg}$ & 5,10 & 0,25 \\
\hline Pig with piglets up to $20 \mathrm{~kg}$ & 6,12 & 0,30 \\
\hline Replacement pigs & 2,50 & 0,14 \\
\hline Piglets from 6 to $20 \mathrm{~kg}$ & 0,41 & 0,02 \\
\hline Piglets from 20 to $50 \mathrm{~kg}$ & 1,80 & 0,10 \\
\hline Piglets from 50 to $100 \mathrm{~kg}$ & 2,50 & 0,14 \\
\hline Fatten pig from $20-100 \mathrm{~kg}$ & 2,15 & 0,12 \\
\hline Boar & 6,12 & 0,30 \\
\hline
\end{tabular}

$$
7344 \mathrm{~m}^{3} \times 1010 \mathrm{~kg} / \mathrm{m}^{3} \times 0.06 \%=445046 \mathrm{~kg} \text { solid }
$$

$$
445046 \mathrm{~kg} \times 0.4 \mathrm{~m}^{3} / \mathrm{kg} \times 1 / 0.65=273875 \mathrm{~m}^{3} \text { biogas }
$$

$$
273875 m^{3} / 365 \text { days }=750.34 m^{3} \text { biogas per day }
$$

The quantity of methane in the biogas has been taken as the usual value of $65 \%$ in volume. The rest of the volume is formed by Carbon Dioxide and Hydrogen Sulphur.

TABLE 3 - Composition of the pig slurry.

\begin{tabular}{|c|c|c|c|c|c|c|}
\hline $\begin{array}{c}\text { Solid } \\
\text { fraction } \\
(\%)\end{array}$ & $\begin{array}{c}\text { Mineral } \\
\text { fraction } \\
(\%)\end{array}$ & $\begin{array}{c}\mathrm{N} \\
(\mathrm{g} / \mathrm{l})\end{array}$ & $\begin{array}{c}\mathrm{P} \\
(\mathrm{g} / \mathrm{l})\end{array}$ & $\begin{array}{c}\mathrm{K} \\
(\mathrm{g} / \mathrm{l})\end{array}$ & $\begin{array}{c}\text { DBO } \\
(\mathrm{g} / \mathrm{l})\end{array}$ & $\begin{array}{c}\mathrm{DQO} \\
(\mathrm{g} / \mathrm{l})\end{array}$ \\
\hline $4-6$ & 1,6 & 4 & 1,2 & 1,7 & 13 & 40 \\
\hline
\end{tabular}

To end up with these calculations, once established the diary quantity of biogas that can be extracted from the farm, it can be defined the energy to recover in form of heat and electric current. This is obtained using the values introduced in table 4 which reflects several values of potential power associated to different kinds of fuels.

$$
750.34 \mathrm{~m}^{3} \times 6500 \mathrm{Kcal} / \mathrm{m}^{3}=4.877 \cdot 10^{6} \mathrm{kcal} / \text { day }
$$

A good quality of biogas has been considered for the calculations of the prototype. This quantity of energy, in electric units is equivalent to $5672 \mathrm{kWh}$ that would be the production per day. From all this values calculated, the tanks and machinery of the plant are selected. One important parameter to decide during the design of the plant is the number of hours in operation everyday since this will determine the size of the different elements of the plant. As the obtained values are not too big, for this case it has been considered to operate $8 \mathrm{~h}$ per day. That means we could produce energy during 8 hours per day with a cogeneration motor with nominal power equal to $709 \mathrm{~kW}$.

TABLE 4 - Comparison of biogas energy power with other fuels used as energy sources

\begin{tabular}{|c|c|}
\hline Fuel & $\mathrm{Kcal} / \mathrm{m}^{3}$ \\
\hline Biogas $\left(65-70 \%, \mathrm{CH}_{4}\right)$ & $5.155-6.622$ \\
\hline Methane & $7.931-9.460$ \\
\hline Carbon Gas & $3.990-4.420$ \\
\hline Natural Gas & $9.293-9.446$ \\
\hline Propane & $19.446-22.982$ \\
\hline Butane & $24.561-30.054$ \\
\hline
\end{tabular}

\section{Biogas plants as a solution}

The biomethanization plants would produce energy and at the same time would help the farmer to get rid of the pig slurry, which means, resolving the problem of the residue. To establish the design of the prototype plant, a large number of papers and web pages have been reviewed [7]-[13].

The biomethanization plant consists on a series of stages where the pig slurry is treated transforming it into different by-products which are separated and profited individually. The whole process can be divided into:

- Reception and pre-treatment area: where the pig slurry is accumulated during non functioning hours and separated from the solids in suspension when passing across the different size grating used to sift the residue.

- Digestion area: the clean pig slurry is introduced into the digester, for this kind of process a digester classified as complete mix digester is used. The pig slurry will have a residence time (THR) of 18 days and the temperature of operation will be of $37^{\circ} \mathrm{C}$, this is in the mesophilic range where the reaction of anaerobic digestion is optimal. From the top of the digester is obtained the biogas. From the bottom some mud that are driven to the composting area. And from the middle of the deposit the residual liquid is transported to the stabilization area where the water gets purified.

- Treatment and stocking biogas area: after leaving the digester the biogas has to be treated in order to reduce its content in water vapour and $\mathrm{H}_{2} \mathrm{~S}$ since no motor could work with the level of sulphur it has in this point of the process. The gas is clean by means of a condenser and a sulphur trap and injected into the gasometer used for balancing purposes (making sure gas pipes operate within a safe range of pressures) and storing the gas for later use (during operation hours of the plant). This will be designed to accumulate the gas produced during three days preventing emergences where the cogeneration motor is stop or non operation days. That represents a volume of $2250 \mathrm{~m}^{3}$.

- Aerobic treatment area: it is used to stabilize water flowing out of the digester. In the stabilization pond the liquid will rest for another 18 days getting purified and being ready for its agrarian use. 




Fig. 4. Mass and energy flowchart of the prototype plant

- Composting and treatment of the digester's mud area: this area comprehends vast surface where all the byproducts obtained from the pig slurry refinement and transformation are subjected to aerobic digestion. The most important part of these by-products is the mud proceeding from the bottom of the digester which suppose around the $10 \%$ of the total mass introduced in it. The resulting product of the aerobic digestion is the well known compost that will be sold as manure supposing a second source of economical incomes.

- Cogeneration system and electric connections: it is responsible for the burning of the gas and production of electricity. The combined performance of the cogeneration group can achieve the $75 \%$ of effectiveness, but the electric efficiency of the combustion motor will seldom reach the $30 \%$. The energy obtained as heat will be used to warm up the digester and allow it working at $37^{\circ} \mathrm{C}$ and for the central heating of the farm if needed. The electric connections will establish the connection between the plant and the EPS. This connection will be normally done in medium voltage for the level of power concerned but that depends strongly on the distribution company where the point of connection has to be done.

- Chimney and torch: are responsible for the evacuation of the exhaust gasses, residual heat and to burn the excess of gas or all of it in case of emergency when it can not fit in the gasometer anymore. It is imperative to remark the importance to burn the methane before leaving it fly free into the atmosphere. When burning the methane carbon dioxide is obtained but this gas is 21 times less contaminant, referred to the green house effect than methane, so it will be always preferably to burn and leave the $\mathrm{CO} 2$ to escape.
A mass and energy flowchart has been developed to show the evolution of the pig slurry along the biomethanization plant, Fig. 4.

From the two products obtained in this plant, a prevision of economical income can be done. An extra income of $8 € / \mathrm{Tm}$ of pig slurry could be received early in the future if public authorities agree to compensate economically those who can help with the pig slurry problem reducing the volume of residue in the region. For the prototype plant introduced in this paper and with the actual regulations, a total income per year of $97174 €$ has been obtained (154000€ with the compensation). On the other hand, construction, engineering and materials for the plant have been estimated on a figure around $650000 €$.

The economic balance of the plant results in a return period of around 7 years, similar results to the models obtained in the American US Environmental Agency web page as examples. That means a return period even shorter than the one, well accepted, for photovoltaic solar plants nowadays, and similar to the return period normally considered for other larger installations such as wind energy farms or thermoelectric plants.

\section{Conclusions}

This paper shows the viability of a methanization plant. A large bibliography has been collected to formulate the paper. It tries to synthesize this information into a clear classification permitting to understand the actual situation of the regulations and the state of technology. A whole prototype plant is introduced, taking into account lots of technical and economical specification which helps to optimize the design. 
Besides, a mass and energy flow-chart corresponding to the evolution of the mass of slurry and the energy obtained in the $\mathrm{AD}$ along the biomethanization plant is shown. The transformations suffered in the different steps get clear in this way as it does the structure of the process itself.

The importance of this kind of installation, in the case of succeeding, would be fundamental to help the autonomic public administration to finish with the problem of the pig slurry.

\section{References}

[1] IEA Bioenergy Task 24: Energy from biological conversion of organic waste.

[2] IEA Bioenergy Task 37: Energy from Biogas and Landfill Gas.

[3] Ley 10/1998 de Residuos, de 21 de abril.

[4] Real Decreto 436/2004, de 12 de Marzo por el que se establece la metodología para la actualización y sistematización del régimen jurídico y económico de la actividad de producción de energía eléctrica en régimen especial.
[5] Real Decreto 324/2000, de 3 de Marzo por el que se establecen normas básicas de ordenación de las explotaciones porcinas.

[6] El Sector Porcino en 2005 - Informe anual Mercolleida.

[7] Plan Integral de Residuos de la Comunidad Valenciana, approved by the Decreto 317/1997 of 24th December and modified by the Decreto 32/1999 of 2nd March.

[8] Ley 54/1997 del sector eléctrico, de 27 de Noviembre.

[9] Flotats, X, Campos, E (2005) "Procesos biológicos: digestión anaerobia y compostaje”, Cap. 9. in Ed. Elias X., Tratamiento y valorización energética de residuos. Ed.Diaz de Santos, Barcelona. ISBN: 84-7978-694-9. Pp 617-686.

[10] Edelman, W., Schleiss, K., Joss, A. (1999). ”Ecologic, energetic and economic comparison of anaerobic digestion with different competing technologies to treat biogenic wastes”, Proceeding of the II International Symposium on anerobic digestion of solid waste (II ISAD-SW), Barcelona, 15-15 June 1999. Volume I, 274-281.

[11] Hobson, P.N. (1990). The treatment of agricultural wastes. Ed. Anaerobic Digestion.

[12] A Waste Treatment Technology. Critical Reports on Applied Chemistry, Volume 31. Elsevier Applied Science, pp 93-138.

[13] Wellinger, A., Lindberg, A. (1999). Biogas upgrading and utilisation. IEA Bioenergy. Task 24: Energy from biological conversion of organic waste. 